\title{
67
}

\section{Using IT to Support Authentic Tasks in Teacher Education}

\author{
Dianne Chambers and Martin Boyle \\ Science \& Mathematics Education, Faculty of Education, The University of Melbourne, VIC \\ 3010 Australia \\ d.chambers@unimelb.edu.au
}

Keywords: teacher education, case studies, teamwork, innovation

\begin{abstract}
Preparing teachers, who will be teaching until perhaps 2040, for classrooms and schools whose technology we can barely imagine is a daunting task. At the Department of Science \& Mathematics Education at the University of Melboume, Australia, a number of projects have been undertaken to allow undergraduate education students to engage in tasks and situations that will foreshadow their experiences as teachers. Online and multimedia resources have been developed that allow students to be projected into their future role as a teacher and it has been found that students respond well to this style of teaching. Observation of student work using these resources shows deeper thinking and enhanced reflective practices in considering how classrooms can be managed and in working as a team.
\end{abstract}

\section{INTRODUCTION}

Education students have been observed to respond well to tasks for which they can see relevance in their future role as teachers. To enhance the learning of students the staff of the Department of Science and Mathematics Education (DSME) at the University of Melbourne, Australia, have developed resources that project undergraduate students into their future role as teachers by setting up authentic tasks and scenarios utilising multimedia. This paper will discuss some of the multimedia resources and a subject developed at the University of Melbourne for use in teacher education in the 
Bachelor of Education (Primary) course. [It should be noted that a number of multimedia resources for authentic tasks have also been developed in the area of mathematics education within DSME - see Chambers and Stacey, (1999) for descriptions.]

The Bachelor of Education (Primary) degree is a four year course of study and is the principal vehicle for the training of primary (elementary $/ \mathrm{K}$ 6) teachers at the University of Melbourne. In 1995 the degree was restructured and updated extensively. This restructuring was accompanied by a substantial reassessment of the direction of the course and of the priorities for competing areas. Furthermore, budget constraints imposed a rethinking of delivery of the course and of the ways in which students undertake practical experience in schools. From the end of 1996, a reduction of $20 \%$ was made in the number of days of supervised practical work in schools ('teaching rounds'). It was therefore an ideal time to invest in revising course delivery in the Bachelor of Education (Primary) degree. Multimedia has the potential to make experience with children a well-integrated part of the university course. In this paper two recent projects in the area of information technology (IT) in education are described. We highlight the ways students engage actively with multimedia resources and the authentic tasks that have been designed to give students 'experiences', skill development, and knowledge about being effective users of IT as a classroom teacher and in being a decision-maker about IT issues in a school. [The term 'student' is used throughout this paper to mean a student in a teacher education course.]

\section{USING MULTIMEDIA IN TEACHER EDUCATION}

\subsection{Computers and the K-6 classroom: Kids can do!}

For the compulsory second year undergraduate subject 'Computers in the Primary Classroom' a resource entitled Computers and the K-6 Classroom: Kids Can Do! (Chambers and Dobbins 1997) was developed in 1996-97 with version 1 being launched late in 1997 (version 2 was released in early 1999, and version 3 is projected for release in 2002). This resource contains lecture notes and workshop activities, over 100 articles about using computers in $\mathrm{K}$ 6 classrooms, demonstration versions of educational software for children, examples of teachers' and children's classroom work with computers, and the Virtual Classroom resource. Kids Can Do! is used as a resource to 
support traditional 'face to face' teaching with a weekly lecture and workshop over an academic year.

The Virtual Classroom was developed using Macromedia's Director program and contains QuickTime VR with embedded video clips of three local classrooms that allows students to view a class in action, and includes interviews with the three classroom teachers (Figure 1). The three classroom models illustrated are: a classroom with two computers; a computer laboratory; and a 'mixed model' of classroom computers plus access to a computer laboratory. Each teacher has a different view on why their style of using computers works for them and for the children in their class. The inclusion of a range of, sometimes contradictory, opinions was deliberate so that our students could see that there are many ways of using computers and associated technologies effectively in classrooms. That is, the effectiveness of the use of computers was dependent not on the number of computers available or the layout of the computers in the room, but rather on how a teacher uses the resources and manages their classroom.

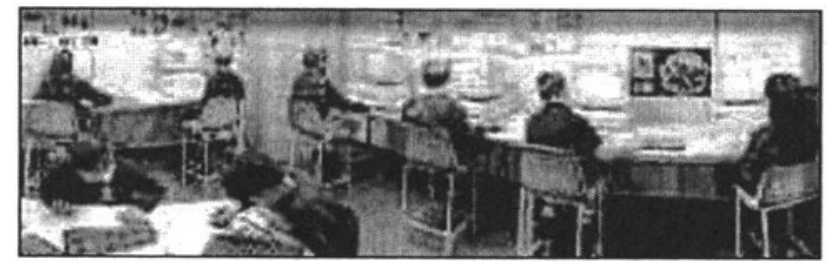

Figure 1. A 'flattened' image from one of the QuickTimeVR photographs from the Virtual Classrooms from 'Computers and the K-6 Classroom: Kids Can Do!' CD-ROM

The Virtual Classroom resource is quite different from many commercially available resources, such as 'Learning about Teaching' (Mousley, Sullivan and Mousley 1996) that shows lessons or lesson segments. The Virtual Classroom resource illustrates classroom activities, as it presents a snapshot in time of all that is going on in a busy classroom. As our students 'move' around the room they can see what each group of children is doing and how the teacher is managing the classroom.

\subsection{Analysing classroom interactions and classroom management}

In the Virtual Classrooms resource our students explore the classrooms of teachers at three schools. The classrooms and teachers were selected as each is using computers effectively across the curriculum, yet there are major differences in how the computers are used and how they are set up in 
(and out of) the classrooms. The observation of classrooms and their workings by our students is made considerably easier through the use of multimedia, as it allows all students to observe exemplary practice in the uses of computers in the classroom. This is something not all students have an opportunity of observing during their time in school experience ('teaching rounds') and the same experience is shared by all classmates. In addition, students can visit and revisit the Virtual Classroom and as their own experience grows they extract new significance from the interactions they observe.

Students investigate aspects of the room in a QuickTimeVR environment and by clicking on 'hotspots' a video clip of an interaction is played. Our second year teacher education students analyse the classrooms in the Virtual Classrooms resource to investigate the interactions and to identify the key issues in classroom management in using computers effectively that are illustrated in the video clips. Students work in pairs for this activity and they engage in thoughtful discussions. Their responses indicate deep reflection on the layout and activities in the classrooms - the level of reflection and focus on the task is often greater than during other activities with these students. Below is an example of a second year undergraduate student's response to an aspect of this task. It indicates both detailed observation and identification of the key issues illustrated in one video clip.

"The classroom was well set-up with different activity tables relating to the same theme. This scene showed how organised the boys were when they had finished their computer task. They immediately went straight to the roster chart, marked it off and checked which activity they had to move to next. It showed them working co-operatively, and they were not distracted as they knew exactly where they had to go next. The roster was placed strategically near the teacher so that she could also keep an eye on who should be where and when. All computers were placed against the back wall, with their wires placed at the back of the tables."

\section{USING PBL AND A SUBJECT WEBSITE FOR LEARNING ABOUT SCHOOL-WIDE IT ISSUES}

During the third and fourth years of the Bachelor of Education (Primary) degree students select one optional subject each year. This allows students flexibility to strengthen an area of interest at an advanced level or to broaden their knowledge in a chosen area. An option that is available in either third or fourth year is the subject 'IT in Primary Schools'. This subject runs over 18 weeks in a weekly two hour block. The subject employs the problem 
based learning [PBL] approach (see Stover 1998, Stepien and Gallagher, 1993) and each problem is explored in a three week cycle (Table 1).

Table 1. Activities during the three week cycle of each problem in the subject 'IT in Primary Schools'

Week 1 (of 3 week cycle)

- $1 \mathrm{~h}$ introduction that raises general issues that may be useful when approaching the problem

- Supported by materials available on subject website including many links to useful sites

- $1 \mathrm{~h}$ workshop where the problem is introduced

- Supporting artefacts, including a rich description of the fictional school and its staff, to support the problem are available on the subject website

Week 2 (of 3 week cycle)

- $2 \mathrm{~h}$ workshop session for teams to work on the problem with staff available to mentor the teams.

- Experts (principals, teachers, and others) are available (via email) to team leaders to gather further information about the problem and solutions/suggestions/ideas. This will provide students with a range of views on the problem and will require development and refinement of questions to ask and interpretation of responses.

Week 3 (of 3 week cycle)

- $2 \mathrm{~h}$ workshop where teams present to the group their recommendations, the style of meeting is similar to a school council meeting.

- Students critique and discuss the recommendations of each team.

- The teams submit a 'Recommendations' document in a format suitable to send to school council members or the principal.

In this subject the students work in teams of five students and tackle five problems involving IT in a primary school over the course of the academic year. The scenario presented to teams is that of committees that are established to respond to a brief developed by the school principal. The team leader is in the role of committee chair and team members as committee members. Teams meet in scheduled class times once each week and are expected to confer - either electronically or in person - outside class time in addition to during class.

The problems include: allocating a budget for IT needs of the school; developing an IT professional development plan for the staff; integrating IT into the curriculum; and, designing the physical layout of a classroom that is about to have IT infrastructure installed. Teams are supplied with a rich description of the (fictional) school and artefacts (such as budget documents, IT skills profiles of staff members, community responses about internet use for children, etc.). These allow them to explore the context of the problem and to tease out aspects of the problem they need to explore and consider. These materials are available to students through the subject's website and may be text, video, or images of 'school documents' as appropriate. In addition to the artefacts, 'experts' are made available for each problem for the team leaders to communicate with via email. These experts are teachers, 
principals or other experts that have some knowledge of some aspects of the problem and experience in how their school has approached a similar problem. They are drawn from the Australian educational community and are experienced educators who have been invited to work with our students to develop their skills and to mentor the students through the problem. In keeping with the problem based learning approach, problems are not so tightly defined that there is a simple answer, and there is no single 'right' answer. It is expected that students will develop recommendations that differ vastly from team to team and that students will learn much from considering and critiquing the recommendations of other teams.

Each team develops recommendations that they present to other teams and to academic staff members in a 'School Council' style of meeting and prepare as a written recommendations, documents for submission. Students take on the role of team leader on a rotating basis and this is where responsibility for compiling and submitting the report and the presentation rests. All students contribute to the team's report of recommendations for all problems (as in the role of committee members). This allows students to have experience in working as a team and in leading a team to meet a deadline. These are highly valued skills for students to develop in addition to the content knowledge developed through exploring each of the problems.

\subsection{Why problem based learning for learning about IT in schools?}

Finkle and Torp (1995) described problem based learning (PBL) as "a curriculum development and instructional system that simultaneously develops both problem solving strategies and disciplinary knowledge bases and skills by placing students in the active role of problem solvers confronted with an ill-structured problem that mirrors real-world problems". This approach for the subject was considered when new graduates (first year teachers) informed us that they were members of the Information Technology Committee (or equivalent) at their school. This is a large role for a new teacher and one for which little of their university studies had prepared them. In response to this need, the subject was developed to give to students experiences in tackling the kinds of IT issues that they may encounter when a teacher, and to experience the role of committee member and chair of a committee with responsibilities for developing a report with recommendations for a school council or principal.

Other powerful learning experiences to support the PBL approach are the individual reflections that each student prepares in the week following the conclusion of each problem. In this document the student reflects on their role in the task and the team process, the activities that facilitated or blocked 
their learning, and their overall response to the learning experience the problem gave them. Following is part of a reflection from the problem about integrating IT into the curriculum, and illustrates the rich experience that can be gained using this approach in teacher education.

"Having to participate in this problem in the hypothetical role of a teacher gave me great insight into my own thoughts and feelings about teaching and learning. I had never consciously applied a teaching philosophy in any of my own work nor assigned a certain style of learning for students to use. Working through this problem enabled me to think about the sort of teacher that I want to be and how I would like my students to learn. Constructivism and PBL model effective teaching practice about teaching and learning."

\subsection{Why use IT to support a PBL subject?}

All subjects taught by the Computers in Education group of the Department of Science and Mathematics Education have a website, including undergraduate subjects (all of which are taught on campus in the 'face to face' mode). The subject web sites are routinely used by students for accessing course materials, including lecture and workshop notes. It was thus natural that materials to support this subject would be delivered online as part of the subject website and the technology allows us to include audio and video and to host electronic discussions to support the problems. Making artefacts that support the problems available through the subject's website also allows us the opportunity to model to our students some ways of using technology to support teaching and learning.

\section{CONCLUSIONS}

The resources that have been developed for undergraduate teacher education studies at the University of Melbourne allow our students to have experiences where they can see exemplary practice in a classroom or investigate how authentic problem involving IT in a school may be solved.

Our experience to date has been that multimedia used in educationally appropriate ways has enhanced our teacher education courses. Using technology in these ways has allowed our students to 'experience' classroom situations where technology is being used in exemplary ways to support children's learning and to analyse situations at a school level and consider alternative solutions or paths of action while working in a team. 
In both of these examples, common elements that strongly influence students' experience and learning are that: (i) students have the opportunity to hear the opinions of practising teachers; (ii) students do not work on these materials alone, but rather must discuss their findings with colleagues; and (iii) that students are given opportunities to reflect on teaching and on their own learning. Connecting with the experiences of exemplary teachers, reflecting on observations and experiences, sharing with others and developing the skills required in being a successful team member will serve our students well in the rapidly changing environment of schools of the twenty first century.

\section{REFERENCES}

Chambers, D. P. and Dobbins, M. (1997) Computers and the K-6 Classroom: Kids Can Do! (CD-ROM) Department of Science and Mathematics Education, University of Melbourne, Parkville, Victoria, Australia.

Chambers, D. P. and Stacey, K. (1999) Technically simple and educationally rich multimedia to support authentic tasks in teacher education. International Conference on Computers in Education (ICCE99). Kisarazu, Chiba, Japan.

Finkle, S. L., and Torp, L. L. (1995) Introductory Documents. Illinois Math and Science Academy. Aurora, Ilinois.

Mousley, J., Sullivan, P. and Mousley, P. (1996). Learning About Teaching. Australian Association of Mathematics Teachers, Adelaide.

Stepien, W. and Gallagher, S. (1993) Problem-based learning: as authentic as it gets. Educational Leadership, April 1993 v50 n7 p. 25(4)

Stover, D. (1998) Problem-Based Learning: Redefining Self-Directed Instruction and Learning. The Forum, Fall 1998, vol. 7, Issue 1.

[http://www.mcli.dist.maricopa.edu/labyforum/Fall98/forum7.html] October 2000.

\section{BIOGRAPHY}

Martin Boyle was educated in the UK and Australia, and after extensive school teaching experience has spent the last five years in teacher education. His research interests include developing learning environments to assist students who are failing in normal school mathematics. 